\title{
An Analysis of Open Source Software Adoption in a Brazilian Nonprofit University
}

\author{
Edmir Parada Vasques Prado ${ }^{1}$ \\ ${ }^{1}$ Escola de Artes, Ciências e Humanidades - Universidade de São Paulo (USP) \\ São Paulo - SP - Brazil \\ eprado@usp.br

\begin{abstract}
Recently, there has been much effort to foster the adoption of Open Source Software (OSS) in several different countries. Studying the characteristics of new users and the reasons that lead them to adopt OSS can thus help better understand this phenomenon, offering lessons to similar projects. In this context, the present paper addresses the adoption of OSS in a Brazilian university. The paper identified distinct groups of students with different preferences in relation to OSS.
\end{abstract}

\section{Introduction}

The Open source software (OSS) phenomenon triggers many interesting questions. OSS users and developers engage in intense voluntary worldwide cooperation leading to community-based continuously evolving systems that can safely be used in critical applications and infrastructure [Nuvolari 2004]. The cooperation among OSS users and developers is maintained through an elaborate infrastructure for sharing knowledge and communication, including issue-reporting/tracking repositories, discussion lists, chat rooms, forums, electronic journals, specialized media and meetings. A strong culture and group behavior have been developed in connection with it, enabled by the Internet [Scacchi et al. 2003]. Due to these characteristics, it is considered by their supporters a paradigm change where the economy of private goods is substituted by the economy of public goods. On the other hand, it has been argued that OSS will always be relegated to niches, and that he cannot compete with their commercial contestant characteristics.

The magnitude of the OSS development rate can be inferred by the steadily growth of Sourceforge.net, the world largest OSS web repository, which in 2000 listed 2370 projects [Elliot and Scacchi 2004] and in 2008 have been hosting more than 180.000 projects. Therefore, it is very difficult to provide an explanation to this new phenomenon, i.e., the development of software, which is continuously perfected, counting with characteristics of technical excellence and freely distributed [Hars and $\mathrm{Ou}$ 2001].

Brazilian Government is trying to improve OSS adoption rate by instructing government ministries and state-run companies to gradually switch to open-source operating systems. Moreover, OSS has been used by government in telecenters that have been dedicated to offering Internet access to Brazilian citizens, thus tackling the country digital divide. According to Vicentin (2007), the number of OSS users in Brazil is still inexpressive due to the lack of applications that can be used by unskilled users. On the other hand, Neto and Augusto (2004) argue that OSS adoption in Brazil is consolidated due to governmental incentives and its use in large organizations. 
The OSS concept is as old as the software industry, but in the last years there is a growing interest on this theme. Studying the characteristics of new users and the reasons that lead them to adopt OSS can help to understand this phenomenon and it can drive the software suppliers in the development of new products. In this context, the present research will study the relationship between undergraduate students profile and their willingness to adopt and use OSS.

The objective of this research is to analyze the adoption of OSS in a non-profit college. Within this context, the research seeks to identify the degree of OSS adoption by students, and examine which concepts of the Theory of Planned Behavior (TPB) have influence on the OSS adoption process.

The remaining of this paper is organized as follows. In Sect. 2 we present our theoretical framework, elaborating on the concept of OSS and on the Theory of Planned Behavior. Sect. 3 thus presents our research design. Sect. 4 we present the methods employed, so that in Sect. 5 we present the results achieved. Lastly, Sect. 6 closes the paper by discussing the results and drawing our conclusions.

\section{Theoretical Foundations}

The concept of OSS was first introduced by Richard Stallman in 1984, aimed at recreating the "open" environment that existed before software vendors decided to distribute executable code for hardware devices without supplying source code with it. Stallman, due to its personal beliefs that computer programs should be shared freely among users, founded the Free Software Foundation in 1984. The objective of this association was to develop and to diffuse a legal mechanism that could guarantee the free access to software developed by programmers interested in sharing them freely with other people. This could simply be made enclosing a license pattern to the developed software establishing these rights. This association should contribute to recreate the characteristics of the "open" environment previously existent [Nuvolari 2004]. The basic license developed by Stallman was GPL (General Public License) [Hippel et al. 2003].

The term Free Software, it is usually confused with the word open source code. It is important to establish a distinction among them:

Free software refers to software whose source code can be freely modified and redistributed. It can be marketed, but its source code should be available for modifications and improvements. Open source code or "open source software" is the trade name adopted starting from 1998 to designate programs whose source code can be modified and distributed without costs. As stated by Elliott and Scacchi (2004), open source is a development methodology and free software is a social movement.

The programs of open code have been used regularly to support network critical applications, including the Internet and Web interfaces. The existent engagement between users and developers, allied to the readiness of the source code allows it to be constantly modified and improved. This process of continuous improvements is facilitated by the communication infrastructures and sharing of knowledge as: discussion forums, newsgroups, repositories, chat rooms and tutorials [Scacchi et al. 2003]. 
The use of OSS is growing steadily in Universities. The "Campus Computing 2003" survey [Green 2003] found that $11.1 \%$ of all network servers in American higher education institutions run on Linux. Another survey conducted by Brazilian researchers in 2003 found that $20 \%$ of corporate low-platform servers in Brazil are based on the Linux operating system [Reinhard and Foresti 2003].

Among the projects known as "open source", one of them deserves a great prominence: the Linux operating system. It was created in Finland, in 1991 by Linus Torvalds, at that time a student of computer science at the University of Helsinki. He was dissatisfied with Windows, the operating system distributed by Microsoft, because it was a proprietary code (it was not possible to modify it). Therefore, he decided to create his own operating system, Linux. Initially, his intention was not the one of creating an operating system to compete with Microsoft Windows. He just wanted to work in something that he judged interesting. He developed the first version of Linux and put it in the Internet so that people could use and modify it. He began then, to receive other programmers' messages with suggestions, of how to improve the system. In little time, the project Linux already counted with more than a thousand programmers, located in several parts of the world, working on it. The motivation to participate in a project like Linux can vary from a simple pastime, or a way of participating in a process of collaborative learning, or even a way to work with some code that is of his interest and to count with the other people's collaboration.

The Open Source community is usually known as "gift culture", characterized by the creation and maintenance of social relationships that are not based on our exchange culture. Therefore, people's importance is evaluated accordingly with their contribution for the community and not for their possessions. Financial compensation doesn't exist for their members, but good developers and leaders count with personal prestige [Markus et al. 2004].

\section{Theory of Planned Behavior}

Different theoretical perspectives try to predict use of Information Systems. According to Todd and Taylor (1995), one important line of research has utilized intention-based models which use behavioral intention to predict usage. Thus, it is helpful to provide an understanding of the determinants of usage. In this field, the Technology Acceptance Model (TAM) has emerged as a powerful model. It tries to explain attitude toward use based on beliefs which are defined by two factors: the perceived ease of use and the perceived usefulness of an information system. It was initially proposed by Davis (1989, 1993) and Davis et al. $(1989,1992)$. TAM has no role for subjective norm (i.e., social influences) and is an adaptation of the Theory of Reasoned Action (TRA) developed by Ajzen and Fishbein (1980).

Another of these well-known intention-based models is the Theory of Planned Behavior, proposed by Ajzen (1991) in psychology, and adapted to the IS field. It is based on the assumption that the intention of using a technology can be identified by attitudes, social influences and facilitating conditions, once they are the determinants of intention of assuming a specific behavior. Moreover, according to this theory, perceived behavioral control constructs described below are direct determinants of behavioral intention:

- Attitude toward the behavior (evaluation of the behavior); 
- Subjective norm (perceived social pressure to conform);

- Perceived behavioral control (perceived ease or difficulty to perform).

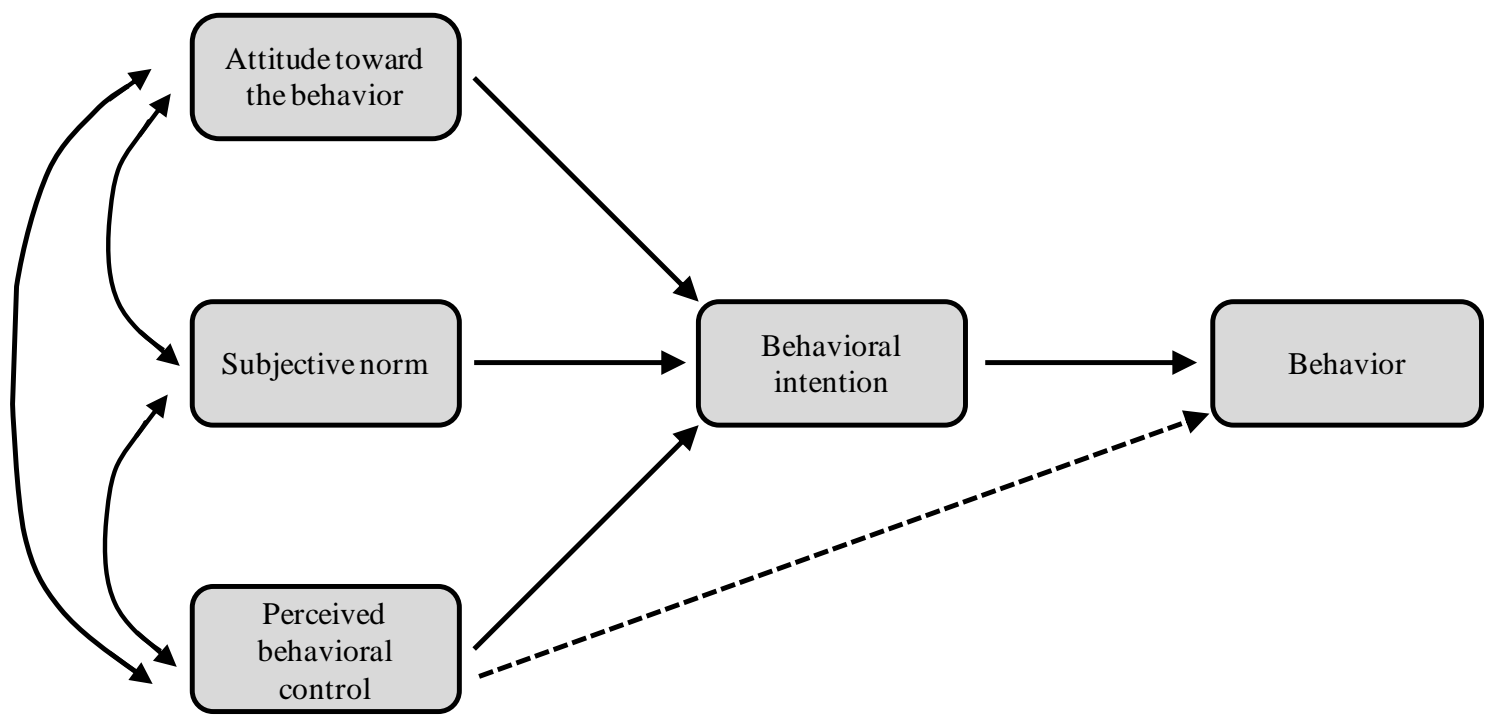

Figure 1. Model of the Theory of Planned Behavior [Ajzen 1991].

TPB can be considered a suitable model for studying the behavior of computer professionals deciding on the adoption of open source software, since their behavior is largely under their "volitional control", i.e., it is essentially their own decision whether or not OSS will be adopted in their departmental computing environments. The change management process aimed at increasing the motivation of the University's students to try the new technology (OSS) by letting it widely available on all microcomputers accessible to them.

The TPB model was chosen based on studies of Taylor et al. (1995) who compared three technology acceptance models: TAM (Technology Acceptance Model), proposed by Davis (1989), TPB and a decomposed version of TPB and concluded that TPB, which adds subjective norms and perceived behavioral control as key determinants for both intention and IT usage, provide a fuller explanation of behavioral intention and IT usage behavior. Since these considerations also apply to USP students OSS adoption, these authors considered TPB to provide more effective guidance to this analysis.

\section{Research Method}

The type of research used in this work can be classified as an exploratory research, according to Marconi and Lakatos (2003). Procedures performed following the recommendations of Franco (1988) and are: literature review; solid theoretical foundation; data collection done at the location of the object of study; storage and data processing; and analysis and interpretation of information collected.

\subsection{Population and Sample}

The object of this research is a nonprofit educational institution located in the metropolitan region of São Paulo. The population studied is composed of students of this institution, and the reason of this choice is due to the fact that they constitute a future skilled labor and they use software intensively. Moreover, they are part of the 
new generation that in the medium term will be occupying decision-making positions in organizations, and have greater capacity to propagate and influence the opinion of future generations.

The population consists of 652 students, from which it obtained a sample of 224 students $(34.4 \%)$ of the four courses offered by this institution: Food Technology, Mechanics for Manufacturing, Business Process and Information Systems Development. It is a non-probability sample, obtained by convenience, but considered the representativeness of each course.

\subsection{Data Collection}

In this study data were collected by applying a questionnaire. The questionnaire was printed and distributed to respondents for them to be filled, but with previous guidance of the applicator. The collection was carried out with the students during the class period, with the permission of a representative of the institution. The respondents were fully informed about the purpose of research before answering it. The advantage of this data collection instrument is the low cost of application, uniformity of measurement, and represents the best way to collect information from a large number of respondents. Data were collected in the second half of 2011.

The questionnaire was developed with self-explanatory questions, clear and aimed at obtaining personal data of respondents, as well as information and knowledge needed to achieve the stated aims of this research.

\subsection{Data Collection}

After collecting the data, the information of 224 questionnaires were transcribed to a spreadsheet (Microsoft Excel). Then the data were refined, excluding those who had not answered crucial questions, or whose response pattern indicated that the student had no interest in answering the survey.

Data analysis was performed in two stages. In the first stage we used descriptive statistics, which include frequency tables. The purpose of this stage was to describe the sample and the characteristics of the population. In the second stage we used cluster analysis to in order to group students based on their preference for OSS and the reasons for its adoption.

\section{Analysis and Discussion of Results}

We obtained 224 questionnaires, of which 26 were excluded because of the lack of: information on age and gender (7); absence of information about the software used (1); and questionable and inconsistent response pattern (18). As a result, 198 questionnaires were used to analyze the adoption of SL.

The results are presented in four parts: (1) Case Setting, (2) Description of the Sample, (3) Adoption of OSS, and (4) Identifying Distinct Students Groups.

\subsection{Case Setting}

The educational institution object of this research belongs to a non-profit foundation, created in the 60 's, in order to cooperate in solving Brazilian educational problems, in order to cooperate in solving the problems of education, and provide assistance and 
protection to people in need. The foundation's activities are based on four pillars - free education, health care, social assistance and aid to housing - and are administered by a Board of Trustees.

In the education sector, the foundation administers an educational center, located in an area of $131000 \mathrm{~m} 2$, founded in the 80's with the proposal to provide free and quality education for all segments of society, from early childhood education, high school and college. In addition, the foundation offers students healthy food, educational materials and uniforms, and meets the different needs of children, youth and adults in the areas of culture, knowledge, sport and leisure.

The educational institute has a technology college, which offers four undergraduate courses of technology: Food Technology (FT); Mechanics for Manufacturing (MM), Business Process (BP); and Information Systems Development (IS). Currently, this educational center has a campus with 652 undergraduate students. It has 250 employees, of which 46 are professors. In the IT area of this education center runs an install base of 800 PCs.

\subsection{Description of the Sample}

Data were tabulated and treated with the SPSS statistical software. Table 1 shows the general characteristics of the sample. The course of IS was shown separately from the

Table 1. Sample Characteristics

\begin{tabular}{|c|c|c|c|c|c|c|c|}
\hline \multirow[t]{3}{*}{ Characteristics } & \multicolumn{7}{|c|}{ Courses } \\
\hline & \multicolumn{3}{|c|}{ IS } & \multicolumn{3}{|c|}{ Others } & \multirow{2}{*}{$\begin{array}{l}\text { Total } \\
\text { (198) }\end{array}$} \\
\hline & $\begin{array}{l}\text { Freshman } \\
\text { (21) }\end{array}$ & $\begin{array}{c}\text { Senior } \\
(42)\end{array}$ & $\begin{array}{l}\text { Total } \\
\text { (63) }\end{array}$ & $\begin{array}{c}\text { Freshman } \\
\text { (46) }\end{array}$ & $\begin{array}{c}\text { Senior } \\
(89)\end{array}$ & $\begin{array}{l}\text { Total } \\
(135)\end{array}$ & \\
\hline \multicolumn{8}{|l|}{ Age } \\
\hline 17 & 9.5 & - & 3.2 & 13.0 & 4.5 & 7.4 & 6.1 \\
\hline 18 & 33.3 & 21.4 & 25.4 & 32.6 & 33.7 & 33.3 & 30.8 \\
\hline 19 & 19.0 & 14.3 & 15.9 & 17.4 & 33.7 & 28.1 & 24.2 \\
\hline 20 & 4.8 & 23.8 & 17.5 & 4.3 & 13.5 & 10.4 & 12.7 \\
\hline 21 & - & 9.5 & 6.3 & 4.3 & 3.4 & 3.7 & 4.5 \\
\hline 22 a 25 & 14.3 & 16.7 & 15.9 & 10.9 & 7.9 & 8.9 & 11.1 \\
\hline$>25$ & 19.0 & 14.3 & 15.9 & 17.4 & 3.4 & 8.1 & 10.6 \\
\hline \multicolumn{8}{|l|}{ Gender } \\
\hline Female & 23.8 & 14.3 & 17.5 & 56.5 & 60.7 & 59.3 & 46.0 \\
\hline Male & 76.2 & 85.7 & 82.5 & 43.5 & 39.3 & 40.7 & 54.0 \\
\hline \multicolumn{8}{|l|}{ Race } \\
\hline White & 81.0 & 78.6 & 79.4 & 69.6 & 71.9 & 71.1 & 73.7 \\
\hline Black & - & - & - & 15.2 & 3.4 & 7.4 & 5.0 \\
\hline Yellow & 14.3 & 4.8 & 7.9 & 4.3 & 4.5 & 4.4 & 5.5 \\
\hline Others & 4.8 & 16.7 & 12.7 & 10.9 & 20.2 & 17.0 & 15.6 \\
\hline \multicolumn{8}{|l|}{ Occupation } \\
\hline Work & 47.6 & 35.7 & 39.7 & 37.0 & 12.4 & 20.7 & 26.7 \\
\hline Stage & & 33.3 & 22.2 & 2.2 & 1.1 & 1.5 & 8.1 \\
\hline Research grant & 14.3 & 2.4 & 6.3 & 4.3 & 7.9 & 6.7 & 6.6 \\
\hline None & 38.1 & 28.6 & 31.7 & 50.0 & 68.5 & 62.2 & 52.5 \\
\hline
\end{tabular}

others, allowing an analysis of the particularities and differences between this course and the others, since this course has software as an important component. In addition, students were divided among freshmen, i.e., first-year students of the university, and seniors, represented by the other students. This separation is intended to allow analysis 
of differences between students who enter college and those who already have influence of the university environment.

The IS course has different characteristics from other courses. Surprisingly, in the sample collected the IS course has $31.8 \%(15.9+15.9)$ of students over the age of 21 years, while the other courses has $17.0 \%(8.9+8.1)$. Another highlight is the minority of only $17.5 \%$ of female students in the IS course, while in other courses, this percentage reaches $59.3 \%$. In relation to race there were no differences between the courses. All presented a predominance of white race.

\subsection{Adoption of OSS}

Students of all university courses were up low on the knowledge of OSS. As shown in Table 2, 89.9\% $(54.0+35.9)$ of students rated their development as low or none. It can be inferred that the environment of the university offered no encouragement to the use of OSS.

Despite the low evolution in OSS knowledge, IS students showed a better evolution than students from other courses. In total, $26.2 \%(23.8+2.4)$ of the IS senior students had regular and good evolution, compared to only $6.7 \%(6.7+0.0)$ of others seniors students. It can be inferred that the difference is due to greater contact IS students have with OSS, through disciplines of IS course and laboratory tasks, among other activities.

The software selected for evaluation of the adoption of OSS was the browser used to access the internet. Firefox and Internet Explorer are offered on equal terms, which make this choice an indicator of adoption made by the student.

Observing the results presented in Table 2, it appears that the adoption of Internet Explorer (69.2\%) is superior to Firefox (30.8\%), and this difference is even greater if we consider only the students of other courses, where $76.3 \%$ of the users adopted Internet Explorer.

Table 2. OSS Adoption

\begin{tabular}{|c|c|c|c|c|c|c|c|}
\hline \multirow{3}{*}{ Characteristics } & \multicolumn{7}{|c|}{ Courses } \\
\hline & \multicolumn{3}{|c|}{ IS } & \multicolumn{3}{|c|}{ Others } & \multirow{2}{*}{$\begin{array}{r}\text { Total } \\
(198)\end{array}$} \\
\hline & $\begin{array}{c}\text { Freshman } \\
\text { (21) }\end{array}$ & $\begin{array}{l}\text { Senior } \\
(42)\end{array}$ & $\begin{array}{l}\text { Total } \\
\text { (63) }\end{array}$ & $\begin{array}{l}\text { Freshman } \\
\text { (46) }\end{array}$ & $\begin{array}{c}\text { Senior } \\
(89)\end{array}$ & $\begin{array}{l}\text { Total } \\
(135)\end{array}$ & \\
\hline \multicolumn{8}{|l|}{ OSS Knowledge } \\
\hline Without evolution & 66.7 & 38.1 & 47.6 & 67.4 & 51.7 & 57.0 & 54.0 \\
\hline Little evolution & 23.8 & 35.7 & 31.7 & 30.4 & 41.6 & 37.8 & 35.9 \\
\hline Regular evolution & 4.8 & 23.8 & 17.5 & 2.2 & 6.7 & 5.2 & 9.1 \\
\hline Good evolution & 4.8 & 2.4 & 3.2 & - & - & - & 1.0 \\
\hline Excellent evolution & - & - & - & - & - & - & - \\
\hline \multicolumn{8}{|l|}{ OSS Adoption } \\
\hline Firefox & 47.6 & 45.2 & 46.0 & 21.7 & 24.7 & 23.7 & 30.8 \\
\hline Explorer & 52.4 & 54.8 & 54.0 & 78.3 & 75.3 & 76.3 & 69.2 \\
\hline
\end{tabular}

\subsection{Identifying Students Distinct Groups}

Using the statistical technique of Cluster Analysis were generated three possible solutions containing from two to four groups. Table 3 shows the solutions generated. We used the ANOVA F test to verify the differences between the groups. The result showed that the best solution is the one with three groups, because it was the solution 
with smaller number of groups and has obtained the largest number of variables with statistical significance less than $5 \%$.

Table 3. Cluster Analysis Alternatives

\begin{tabular}{|c|c|c|c|c|c|c|c|c|c|c|c|c|}
\hline \multirow{3}{*}{$\begin{array}{l}\text { Alternatives } \\
\text { considered }\end{array}$} & \multirow{2}{*}{\multicolumn{4}{|c|}{$\begin{array}{l}\text { Number of students } \\
\text { in each group }\end{array}$}} & \multicolumn{8}{|c|}{ TPB Concepts } \\
\hline & & & & & \multicolumn{4}{|c|}{ Perceived behavioral control } & \multicolumn{2}{|c|}{ Subjective norms } & \multicolumn{2}{|c|}{ Attitude } \\
\hline & I & II & III & IV & $\begin{array}{c}\text { Ease of } \\
\text { use }\end{array}$ & $\begin{array}{l}\text { Perfor- } \\
\text { mance }\end{array}$ & $\begin{array}{l}\text { Usa- } \\
\text { bility }\end{array}$ & $\begin{array}{l}\text { Compa- } \\
\text { tibility } \\
\end{array}$ & $\begin{array}{c}\text { Influ- } \\
\text { ence }\end{array}$ & $\begin{array}{l}\text { Impo- } \\
\text { sition }\end{array}$ & $\begin{array}{c}\text { Agree- } \\
\text { ment }\end{array}$ & $\begin{array}{l}\text { Secu- } \\
\text { rity }\end{array}$ \\
\hline 2 groups & 33 & 28 & & & $0.040^{(\mathrm{a})}$ & 0.002 & 0.620 & 0.002 & 0.000 & 0.000 & 0.001 & 0.012 \\
\hline 3 groups & 17 & 15 & 29 & & 0.000 & 0.000 & 0.000 & 0.000 & 0.000 & 0.000 & 0.001 & 0.049 \\
\hline 4 groups & 14 & 15 & 5 & 27 & 0.000 & 0.000 & 0.000 & 0.000 & 0.000 & 0.000 & 0.001 & 0.138 \\
\hline
\end{tabular}

Legend: (a) statistical significance.

After identifying the best alternative (three groups) we did an analysis to describe the characteristics of students in each Group, and check those that distinguish a particular group from others. To make this distinction, we used the chi-square test. These values are presented in Table 4 . Values less than 5\% have statistical significance.

Students who adopted OSS were grouped due to reasons related to two TPB concepts. The groups in Table 4 are:

- Group I (youth group). The group adopted OSS based on the TPB concept of Attitude. This group is composed by a majority of new students $(52.9 \%$ are under 18 years of age) and most of white race. This seems to indicate that if educational institutions and government invest in programs to change Attitude of the younger students, this can increase OSS adoption;

- Group II (technical group). This group adopted OSS based on the TPB concept of Perceived Behavioral Control. This is a group formed by the majority of males, with yellow race, and of IS course. This indicates that groups that adopt OSS for technical reasons are very particular groups. Investments to disclose OSS technical characteristics should have little effect on increasing OSS adoption;

- Group III (motivated group). This group adopted OSS due to the three concepts of TPB. This is a group highly motivated to use OSS and composed of students that are not from de IS course. Any initiative of the government or educational institutions to disclose OSS tends to be positive in increasing de use of OSS for this group. 
Table 4. Characteristics of the students groups

\begin{tabular}{|c|c|c|c|c|c|c|c|}
\hline \multirow{2}{*}{\multicolumn{2}{|c|}{ Group }} & \multirow[t]{2}{*}{ Variables } & \multirow[t]{2}{*}{ Category } & \multicolumn{3}{|c|}{ Group Frequency $(\%)$} & \multirow{2}{*}{$\begin{array}{l}\text { Statistical } \\
\text { Significance }\end{array}$} \\
\hline & & & & I (17) & II (15) & III (29) & \\
\hline \multirow{11}{*}{\multicolumn{2}{|c|}{ Personal characteristics }} & \multirow[t]{2}{*}{ Course } & IS & 47,1 & 73,3 & 34,5 & \multirow{2}{*}{0,056} \\
\hline & & & Others & 52,9 & 26,7 & 65,5 & \\
\hline & & \multirow[t]{3}{*}{ Age } & $<=18$ & 52,9 & 33,3 & 31,0 & \multirow{3}{*}{0,430} \\
\hline & & & $<=21$ & 23,5 & 46,7 & 51,7 & \\
\hline & & & $>21$ & 23,5 & 20,0 & 17,2 & \\
\hline & & \multirow[t]{4}{*}{ Race } & Yellow & 0,0 & 13,3 & 0,0 & \multirow{4}{*}{0,316} \\
\hline & & & White & 82,4 & 60,0 & 69,0 & \\
\hline & & & Black & 0,0 & 6,7 & 3,4 & \\
\hline & & & Others & 17,6 & 20,0 & 27,6 & \\
\hline & & \multirow[t]{2}{*}{ Gender } & Female & 41,2 & 26,7 & 51,7 & \multirow{2}{*}{0,299} \\
\hline & & & Male & 58,8 & 73,3 & 48,3 & \\
\hline \multirow{5}{*}{\multicolumn{2}{|c|}{ Maturity }} & \multirow[t]{2}{*}{ School } & Freshman & 35,3 & 20,0 & 37,9 & \multirow{2}{*}{0,525} \\
\hline & & & Senior & 64,7 & 80,0 & 62,1 & \\
\hline & & \multirow[t]{3}{*}{ Professional } & None & 47,1 & 33,3 & 62,1 & \multirow{3}{*}{0,656} \\
\hline & & & Stage & 35,3 & 33,3 & 13,8 & \\
\hline & & & Work & 17,6 & 33,3 & 24,1 & \\
\hline \multirow{9}{*}{\begin{tabular}{|l} 
TPB \\
concepts \\
(Degree of \\
influence in \\
choosing \\
OSS)
\end{tabular}} & \multirow{6}{*}{$\begin{array}{l}\text { Subjective } \\
\text { norms }\end{array}$} & \multirow[t]{3}{*}{ Influence } & Low & 52,9 & 86,7 & 24,1 & \multirow{3}{*}{$\mathbf{0 , 0 0 0}$} \\
\hline & & & Medium & 41,2 & 13,3 & 24,1 & \\
\hline & & & High & 5,9 & 0,0 & 51,7 & \\
\hline & & \multirow[t]{3}{*}{ Imposition } & Low & 41,2 & 100,0 & 6,9 & \multirow{3}{*}{$\mathbf{0 , 0 0 0}$} \\
\hline & & & Medium & 41,2 & 0,0 & 62,1 & \\
\hline & & & High & 17,6 & 0,0 & 31,0 & \\
\hline & \multirow[t]{3}{*}{ Attitude } & \multirow[t]{3}{*}{ Agreement } & Low & 11,8 & 40,0 & 3,4 & \multirow{3}{*}{$\mathbf{0 , 0 0 2}$} \\
\hline & & & Medium & 58,8 & 46,7 & 34,5 & \\
\hline & & & High & 29,4 & 13,3 & 62,1 & \\
\hline
\end{tabular}

Legend: (*) chi-square test

\section{Conclusion}

This paper analyzed the adoption of Open Source Software (OSS) in a nonprofit educational institution located in the metropolitan region of São Paulo. We verified that there was a low adoption of OSS by students, what indicates an absence of strategy to promote the use of OSS.

In order to better understand what kind of student adopted OSS, we conducted a Cluster Analysis. The result showed three groups identified as "Youth Group", "Technical Group" and "Motivated Group". From the observation of the characteristics of each group, we could infer that the Attitude, one of the TPB concepts, is the concept that showed better efficacy in the understanding of students OSS adoption, especially the younger ones. This result shows that if the government intends to increase the adoption of OSS, it would be more efficient to invest in programs for young college students with content related to the TPB concept of Attitude. 


\section{References}

Ajzen, I. (1991). The Theory of Planned Behavior. In Organizational Behavior and Human Decision Processes, 50, p. 179-211.

Davis, F. D. (1989). Perceived Usefulness, Perceived Ease of Use, and User Acceptance of Information Technology. In MIS Quarterly, September.

Davis, F. D. (1993). User Acceptance of Information Technology: System Characteristics, User Perceptions and Behavioral Impacts. In International Journal of Man Machine Studies, 38, p. 475-487.

Davis, F. D., Bagozzi, R., P. and Warshaw, P. R. (1989). User Acceptance of Computer Technology: A Comparison of Two Theoretical Models. In Management Science, 35, 8, p. 982-1003.

Davis, F. D., Bagozzi, R., P. and Warshaw, P. R. (1992). Extrinsic and Intrinsic Motivation to Use Computers, in the Workplace. In Journal of Applied Social Psychology, 22, p. 1111-1132.

Elliot, M. S.; Scacchi, W. (2004) "Free Software Development: Cooperation and Conflict in a Virtual Organizational Culture". In: Free /Open Software Development, Edited by Koch, S., IDEA Publishing.

Franco, M. L. P. B. (1988). Porque o conflito entre as tendências metodológicas não é falso. In Cadernos de Pesquisa. São Paulo: n. 66, p. 75-80.

Green, K.C. (2003). The 2003 campus computing survey. Encino, CA: Kenneth Green/Campus Computing.

Hair Jr., J. F., Anderson, R. E., Tatham, R. L. and Black, W. C. (1998), Multivariate Data Analysis, Prentice Hall, $5^{\mathrm{a}}$ edição.

Hars, A. and Ou, S. (2001). Working for Free? - Motivations of Participating in Open Source Projects. In Proceedings of the $34^{\text {th }}$ Hawaii International Conference on System Sciences.

Marconi, M. A. and Lakatos, E. M. (2003), Fundamentos da Metodologia Científica, Atlas, $5^{\mathrm{a}}$ edição.

Markus, M.L., Manville, B. and Agres, C. (2004) "Virtual Organization Design Lessons From the Open Source Movement.", http://web.bentley.edu/empl/m/ Imarkus/Markus_Web_Documents_(pdf)/Virtual_Organization_Open_Source.pdf.

Mcdowell, I. and Newell, C. (1987), Measuring health: A guide to rating scales and questionnaires, Oxford University Press.

Neto, C. and Augusto, M. P. (2004). A study on the motivation of Brazilian open source software users and developers. In Proceedings of the $28^{\text {th }}$ ANPAD, Curitiba.

Nuvolari, A. (2004) “Open source software development: Some historical perspectives", http://opensource.mit.edu/papers/nuvolari.pdf.

Scacchi, W., Gasser, L., Ripoche, G. and Penne, B. (2003). Understanding continuous design in F/OSS Projects. In Proceedings of the $16^{\text {th }}$ International Conference On Software and Systems Engineering and its Applications (ICSSEA-03), Paris, France. 
Taylor, S and Todd, P. A. (1995). Understanding Information Technology Usage: A Test of Competing Models. In Information Systems Research 6, 2, p. 144-176.

Vicentin, I. C. (2007). Open source software development in Brazil: a study about the perception of the people involved and the ideological and business motivations, $\mathrm{PhD}$ thesis of the Business School at the University of São Paulo, Brazil. 